\title{
A poluição sonora e o ensino de física
}

\author{
Noise pollution and physics teaching
}

\author{
Maria Lúcia Netto Grillo*1@, Felipe da Silva Freitas ${ }^{2}$ \\ ${ }^{1}$ Universidade do Estado do Rio de Janeiro, Rio de Janeiro, RJ, Brasil. \\ ${ }^{2}$ Competente Curso Preparatorio LTDA, Niteroi, RJ, Brasil.
}

Recebido em 21 de agosto de 2021. Aceito em 21 de outubro de 2021.

\begin{abstract}
O ensino de Física vem sofrendo diversas mudanças, principalmente, no que diz respeito aos avanços nas pesquisas destinadas para esse fim. Entretanto, críticas em relação ao ensino dessa disciplina, bem como alto índice de reprovação, podem ser observados cotidianamente no contexto escolar. Diversas são as causas para essa situação. No sentido de apresentar uma proposta educacional contemporânea, voltada à formação do estudante para o exercício pleno da cidadania, na perspectiva de uma aprendizagem significativa, este trabalho visa à aproximação entre a Física e o Meio Ambiente, a partir da temática Poluição sonora e suas consequências na vida cotidiana. Foi proposta uma atividade problematizadora, com o intuito de conscientizar os estudantes sobre os efeitos causados pelo uso de fones de ouvido em volumes elevados. A fim de construir a resposta científica com os alunos, considerando o nível de intensidade sonora, foi proposta uma atividade baseada em questionários, exposições, problematização, textos, vídeos e no final um experimento no qual, com o uso de sonômetro, deviam fazer a medida do nível de intensidade sonora dos seus fones de ouvido a partir do volume mínimo até chegar ao máximo, para perceberem que não é conveniente usar o volume máximo para ouvir suas músicas.
\end{abstract}

Palavras-chave: Ensino de Física; poluição sonora; aprendizagem significativa; nível de intensidade sonora.

Physics teaching has undergone several changes, especially regarding to advances in research designed for this purpose. However, critics of the teaching of this discipline, as well as high rate of failure, can be seen daily in the school context. There are some causes for this situation. In order to present a contemporary educational proposal, aimed at training students for the full exercise of citizenship, in the perspective of meaningful learning, this work aims to bring physics and the environment closer, based on noise pollution and its consequences in everyday life. A problematizing activity was proposed, in order to make students aware of the effects caused by the use of headphones at high volumes. In order to build the scientific response with the students, considering the sound intensity level, they are proposed to carry out an activity based on questionnaires, exhibitions, problematization, texts, videos and at the end an experiment in which, with the use of a sonometer, they must do the measure of the sound intensity level of your headphones in a gradual way from the minimum volume to the maximum, to realize that it is not convenient to use the maximum volume to listen to their music.

Keywords: Physics teaching; noise pollution; meaningful learning; sound intensity.

\section{Introdução}

O ensino de Física vem passando por diversas mudanças, principalmente, em relação às pesquisas destinadas para essa finalidade. Porém, críticas em relação ao ensino dessa disciplina, bem como um índice elevado de reprovação podem ser observados cotidianamente no contexto escolar. Tais críticas são reforçadas por práticas educacionais centradas no professor, onde o aluno participa passivamente das aulas, sem até mesmo refletir sobre o que está sendo ensinado em sala de aula e suas respectivas relações com a vida fora dali. No sentido de apresentar uma proposta de atividade didática contemporânea, voltada para a formação do estudante para o exercício pleno da cidadania, esse trabalho visa evidenciar as aproximações entre a Física e a poluição sonora. Com o objetivo de conscientizar os es-

\footnotetext{
*Endereço de correspondência: marialucia@grillo.com.br
}

tudantes sobre as consequências e impactos dessa forma de poluição, bem como fornecer-lhes meios para uma intervenção consciente em tais problemas, foi proposta uma atividade problematizadora, na qual a poluição sonora será discutida a partir da exploração do conteúdo científico de Física.

No ensino de ciências é importante refletir se o que se ensina na escola será aplicado fora dali, e consequentemente sobre sua contribuição para a formação dos alunos.

O ensino oferecido nas instituições escolares está ainda distante da realidade vivida pelos alunos e, sendo assim, assuntos com grande relevância para a sociedade contemporânea são muitas vezes deixados de lado. Essa forma de percepção dos conteúdos escolares não oferece subsídios para que os alunos possam enxergar a Física fora do ambiente escolar. Além disso, gera, ou pelo menos contribui para o desinteresse da maioria dos alunos. Essa falta de interesse acaba se tornando um 
dos principais obstáculos para uma aprendizagem com significado para a vida.

Nessa perspectiva, como caminho necessário para uma contextualização que retorne à realidade, uma problematização é vista como fundamental nesse processo, pois ajuda a refletir sobre a realidade ou parte dela, sistematizando o conhecimento.

Num contexto histórico, a revolução industrial, introduziu uma série de novos sons dos quais o mundo está exposto até hoje. Conforme a norma ABNT-NBR 16.313 [1], ruído é todo som que pode causar incômodo, ser indesejável ou não inteligível.

A poluição sonora pode ser definida [2], legalmente, como "a degradação da qualidade ambiental resultante de atividades que direta ou indiretamente lancem energia em desacordo com os padrões ambientais estabelecidos". Além disso: prejudica a saúde e bem-estar da população, afeta as relações sociais entre os indivíduos, bem como pode causar desvalorização de imóveis e afetar a comunicação entre os animais, além de provocar estresse e outros efeitos orgânicos.

A audição, um dos principais canais de comunicação do ser humano, é um dos meios de percebermos os danos ocasionados pela exposição excessiva a esse tipo de poluição. Quando não diagnosticado em tempo, o dano auditivo tem efeitos muitas vezes irreparáveis, causando sérios problemas de modo a interferir no desenvolvimento social e intelectual de um indivíduo. E esse não é o único possível dano à saúde que pode ser causado pela poluição sonora. Em Clark e outros [3] encontramos a diabetes como uma das consequências. Outras referências sobre os problemas na saúde devidos à poluição sonora falam sobre hipertensão 4, efeitos cardiovasculares em trabalhadores da indústria [5], impacto da poluição sonora na saúde infantil [6] e consequências do ruído sobre o adoecimento [7]. Ambientes urbanos estão sujeitos a diversos ruídos, devidos ao tráfego de automóveis, ônibus e trens, dentre outros, principalmente nas regiões próximas a estradas, rodoviárias e estações de trens. Os locais próximos a aeroportos passam por dificuldades ainda maiores, devido ao som de alta intensidade produzido pelos aviões.

Sendo bastante negligenciado, o aspecto sonoro em nosso ambiente é levado em conta somente no caráter trabalhista - a norma regulamentadora NR 15 [8 apresenta os níveis máximos permitidos do som e seus respectivos tempos -, pois existe pouco material divulgado para a população. Sendo assim, torna-se necessário discutir poluição sonora e seus aspectos e impactos na saúde humana e no meio ambiente, de modo a apresentar formas de controle e prevenção desse tipo de poluição.

Nessa perspectiva, o ambiente escolar ganha espaço, pois é o meio onde estão os indivíduos em formação, com a oportunidade de formar cidadãos críticos aptos a intervir em questões de demanda social, tendo por base uma proposta educacional contemporânea, voltada à formação do estudante para o exercício pleno da cidadania.

Para isso, a aproximação entre a Física e as questões relativas ao som se faz necessária, pois por meio desta é possível compreender de forma conceitual e experimental os aspectos ligados ao som e suas interações com a vida humana. Além disso, por ser uma proposta contemporânea, o estudante terá a oportunidade de ver a Física como ela realmente é, ampla, diversificada e atual, mostrando que é muito além de fórmulas e resolução repetitiva de exercícios, mas que sua compreensão requer leitura e uma interação interdisciplinar com outras áreas de conhecimento.

As normas ABNT NBR 10151 [9] e ABNT NBR 10152 [10, estabelecem os níveis adequados do som e procedimentos técnicos que devem ser adotados na medição de níveis de pressão sonora em ambientes internos e externos de edificações, respectivamente, onde são recomendados limites menos restritivos para períodos diurnos em relação aos noturnos.

Trazendo a política educacional para o âmbito escolar, a proposta desse trabalho ganha espaço no que diz respeito às competências gerais da Educação Básica propostas pela Base Nacional Comum Curricular (BNCC) [1]. Esse documento determina as competências (gerais e específicas), as habilidades e as aprendizagens essenciais que todos os alunos devem desenvolver durante cada etapa da Educação Básica. A BNCC não deve ser entendida como sinônimo de currículo, mas que está diretamente ligada à construção dos currículos Estaduais e Municipais, bem como ao projeto político pedagógico e ao currículo das escolas. Seu objetivo é garantir a todos os estudantes o direito de aprender um conjunto fundamental de conhecimentos e habilidades comuns, de modo a reduzir as desigualdades educacionais no país, de forma a nivelar e elevar a qualidade do ensino. Além disso, ela visa formar estudantes com habilidades e conhecimentos considerados essenciais para o século XXI, de modo a incentivar e permitir uma modernização dos recursos e das práticas pedagógicas e atualização do corpo docente. Dentre diversos aspectos, a BNCC contempla uma proposta de ensino voltada para formação do cidadão, visando à sociedade como um todo, onde conhecimentos historicamente construídos sobre o mundo físico, cultura e social são valorizados com o objetivo de entender e explicar a realidade. Além disso, por meio de tal proposta é possível exercitar a curiosidade intelectual e recorrer à abordagem prática das ciências incluindo a investigação, a reflexão, a análise crítica, a imaginação e a criatividade, de modo a contemplar meios diversos, incluindo várias áreas de conhecimento para solução de problemas e tendo suas escolhas alinhadas ao exercício da cidadania e ao seu projeto de vida, com liberdade, autonomia, consciência crítica e responsabilidade.

A poluição sonora promove a argumentação de fatos, dados e informações, com o intuito de formalizar ideias, defender pontos de vista e tomada de decisões comuns 
que respeitem e promovam os direitos humanos, a consciência socioambiental e o respeito aos níveis de intensidade sonora em âmbito local, regional e global, possibilitando uma consciência crítica e com responsabilidade.

Seres humanos sempre sofreram incômodos de sons muito intensos, mas só após a revolução industrial o tema passou a ser reconhecido como um problema mundial de saúde pública, quando uma perda significativa da capacidade auditiva passou a ser apresentada por operários, afetando consequentemente em sua capacidade produtiva. Mas foi só na década de 60 que a poluição sonora urbana passou a ser tratada como uma questão de saúde pública.

Ainda que somente o ruído ocupacional seja considerado lesivo, há outros que causam perdas auditivas e danos à saúde do indivíduo, como ocorre com sons acima de 85 decibels. Tal limite é o máximo de exposição que uma pessoa pode ter em uma jornada de oito horas de trabalho [8]. Segundo Ladeia [12], a poluição sonora é considerada atualmente a terceira maior causa de poluição do mundo moderno.

Atualmente, a poluição sonora é oficialmente, um problema de saúde pública. No Brasil, as resoluções do Conselho Nacional de Meio Ambiente (CONAMA 001 e 002/90) demostram que:

\section{o excesso de som é um problema de saúde pública, o qual afeta a qualidade de vida e é agravado com a evolução industrial e tecnológica. Visando ao controle do excesso de ruído, a resolução 002/90 estabeleceu o Programa Nacional intitulado Educação e Controle da Poluição Sonora [13].}

A poluição sonora não é um fenômeno recente, mas algo que está presente na humanidade desde os tempos mais remotos, das mais variadas origens e características físicas, e tem aumentado nos tempos modernos. Na natureza são produzidos ruídos dos mais diversos, tais como tormentas, furacões e tornados. No entanto, os mais alarmantes e agressivos são recorrentes de atividades humanas, concentradas em meios urbanos e ambientes de trabalho.

Fica cada vez mais evidente, por meio de diversos estudos realizados ao longo das últimas décadas em todo o mundo, que este tipo de poluição afeta a saúde humana nos variados contextos provocando uma série de efeitos fisiológicos e psicológicos. Tanto por parte dos órgãos de gestão como dos próprios cidadãos não se dava a atenção devida ao estudo da contaminação sonora e de seus efeitos. Tal comportamento pode ser entendido pelo fato de os efeitos não serem imediatos e os ruídos estarem associados a atividades indispensáveis na forma de vida moderna.

Nas últimas décadas o Brasil tem apresentado uma série de similaridades com outros países no que diz respeito aos níveis de poluição, tanto países em via de desenvolvimento como até mesmo nos desenvolvidos.
Um considerável incremento nos níveis de ruído pode ser apresentado por cidades brasileiras e suas regiões metropolitanas, quase sempre como consequências dos movimentos migratórios. Nessa perspectiva, um conjunto de ações acadêmicas e informativas geram questionamentos sobre esse tipo de problema que, embora em número reduzido, chegam aos veículos de comunicação e chamam a atenção da população local, conscientizando sobre os danos causados à própria vida.

A comunidade científica exerce um papel de extrema importância na conscientização da população acerca dos efeitos causados pela contaminação sonora. Por meio dela são feitas produções acadêmicas com a finalidade de mostrar para a população que em situações corriqueiras do cotidiano estão presentes fenômenos que a longo prazo causam efeitos maléficos à saúde humana, que com medidas preventivas podem ser evitados, elucidando o caráter inclusivo da ciência, que ela é para todos. Desse modo, a população exerce plenamente a cidadania, pois é capaz de compreender que suas tomadas de decisões interferem tanto no contexto pessoal como social, melhorando a qualidade de vida. Tal conscientização pode ser realizada não somente via canais de comunicação mais tradicionais, como também via ambiente escolar, onde o indivíduo vive a fase mais importante do seu processo de formação e desenvolvimento cognitivo.

No que diz respeito à produção científica relativa ao ruído ambiental e suas vertentes, nos últimos 15 anos o Brasil cresceu de forma expansiva, fato evidenciado, por exemplo, pelo número de trabalhos apresentados no XXVIII Encontro da Sociedade Brasileira de Acústica [14].

O presente trabalho apresenta aproximações entre a Física e a Poluição sonora, na qual a temática é discutida a partir da exploração do conteúdo científico de Física no currículo do Ensino Médio.

\section{Educação Ambiental e Ensino de Física na Perspectiva da Pesquisa em Educação em Ciências}

A Física, por sua própria condição de ciência básica, oferece conceitos e modelos para a compreensão dos fenômenos naturais. Assim, discussões relacionadas às problemáticas ambientais não podem ser devidamente compreendidas sem a sua contribuição.

A análise de questões relacionadas ao Meio Ambiente, bem como, a proposição de soluções, exige um olhar multidisciplinar, ou seja, há a necessidade de estabelecimento de relação com outras Ciências, tais como: Química, Biologia, Economia e Sociologia. Desse modo fica evidente a característica transdisciplinar presente nas diversas formas do conhecimento.

Sendo a Física umas das mais abrangentes Ciências, a sua função tem devida importância para o desenvolvimento científico, desse modo, sendo amparada ou amparando outras disciplinas. O entendimento de problemas mais complexos possui como base essencial 
a interdisciplinaridade com participação da Física, podendo dessa forma, encontrar soluções beneficiando vários segmentos da sociedade.

Ao tratar dos problemas ambientais, Landulfo [15 faz uma boa síntese:

Os problemas ambientais, em síntese, consistem na configuração de muitas diferentes variáveis, fatores negativos que despontam e crescem através do tempo, nos diversos ecossistemas do planeta, colocando em perigo por vezes de forma ameaçadora e apocalíptica - a sobrevivência da espécie humana, a perpetuação da vida e a integridade do globo terrestre.

Na perspectiva de um ensino de Física que contribua para uma melhor educação dos alunos do Ensino Médio, Leodoro e Santos [16] consideram que "a natureza dual da ciência enquanto instituição concreta e, portanto, inserida permanentemente num jogo de múltiplos interesses" não pode ser descartada. Assim, esses autores defendem que "o desafio da educação ambiental no ensino de física implica em promover a problematização da ciência enquanto agente de contribuição ao estado crítico do ambiente contemporâneo".

A contextualização e a interdisciplinaridade são citadas nos documentos oficiais do MEC e estão cada vez mais presentes nos discursos educacionais, entretanto, a sua utilização não tem se mostrado como prática corriqueira na escola. Nos PCN é considerado como viável "[...] generalizar a contextualização como recurso para tornar a aprendizagem significativa ao associá-la com experiências da vida cotidiana ou com os conhecimentos adquiridos espontaneamente" [17.

\section{A Aprendizagem Significativa e as Metodologias Ativas na Perspectiva do Ensino de Ciências}

No contexto do ensino de Física, o som e algumas características já estão presentes na estrutura cognitiva do indivíduo, servindo desse modo, de subsunçores, conforme o modelo de Ausubel [18, para os conceitos de amplitude sonora, frequência sonora e timbre, tendo como consequência o desenvolvimento e modificação do conceito de subsunçor por meio da aprendizagem significativa. Contrapondo essa ideia, a aprendizagem definida por Ausubel como mecânica possui pouco ou até mesmo nenhuma relação com os subsunçores existentes na estrutura do aluno, não promovendo o seu aprimoramento. A memorização de fórmulas, leis e conceitos físicos pode ser caracterizada como esse tipo de aprendizagem, por mais que possa ocorrer algum tipo de associação. Uma aprendizagem por descoberta e por percepção se complementam, fazendo com que após a descoberta a aprendizagem só se torne significativa se o conteúdo descoberto estabelecer ligação com os subsunçores, de modo a ser incorporada à estrutura cognitiva de forma não arbitrária.

Num contexto onde não há existência de subsunçores, se faz necessário refletir sobre sua formação, origem e como tornar algo que já foi aprendido mecanicamente em um elemento significativo. Para que essa aprendizagem ocorra é preciso que o assunto objeto de estudo seja relacionado ou até mesmo incorporado à estrutura cognitiva do aprendiz de modo não arbitrário, fazendo com que as ferramentas utilizadas no processo sejam potencialmente significativas. No entanto, não basta que somente as ferramentas tenham essas características, mas que também o aprendiz esteja disposto a utilizálas de forma não arbitrária e sem a intensão de somente memorizar os processos, pois a aprendizagem pode se tornar mecânica mesmo o material sendo potencialmente significativo. Reciprocamente, o fato de o indivíduo estar disposto a aprender não garante que o processo será significativo, pois depende se o material será potencialmente significativo.

A formação de um indivíduo reflexivo e crítico diante de questões sociais envolve práticas pedagógicas que vão além de descentralizar o professor no processo educativo, mas envolvem todo o contexto no qual está inserida e de modo a contemplar uma formação profissional continuada em que o professor acompanhe as mudanças no que diz respeito às tendências pedagógicas modernas. No contexto das mudanças curriculares não basta somente passar de uma área específica para a interdisciplinaridade, mas também apresentar estratégias de ensinoaprendizagem que são como um desafio para a formação de professores do futuro, tais como metodologias ativas. Há necessidade de que a criatividade do professor seja estimulada por meio de atividades que correlacionem teoria e prática buscando atender às necessidades da sociedade e aprimorando suas práticas levando em conta que o método tradicional deixa de atender demandas sociais, tornando-se sem eficiência no processo educativo. A aprendizagem ativa vem como meio pelo qual processos construtivos são estimulados por processos que envolvam prática e reflexão, tornando o estudante ativo no papel que diz respeito ao seu aprendizado por meio de experiências e desafios que o permitem encontrar soluções e desenvolver soluções reais.

A divergência entre o perfil dos alunos atuais e o modelo de ensino se configura como um dos principais desafios enfrentados pelos professores para promover uma aprendizagem significativa [19]. Professores de diversas áreas, em particular do ensino de Física, vêm empregando esforços para mudar a sala de aula a fim de torná-la mais ativa. A aprendizagem ativa envolve atividades que possibilitam ao aluno o engajamento cognitivo e a reflexão ao longo do processo sobre suas ações.

A Sala de Aula Invertida (Flipped Classroom) vem se destacando como uma das diversas formas possíveis de 
se implementar uma aprendizagem ativa. Nesse modelo, ocorre contato dos alunos com os tópicos a serem discutidos em sala de aula por meio de atividades que antecedem às aulas, podendo ser feitas em casa, por exemplo, leituras e visualização de vídeos. Nesse sentido, o papel do professor tem um novo significado, pois o ensino é centrado nos alunos que contribuem de forma colaborativa na elaboração das aulas.

A Sala de Aula Invertida não é algo inédito e não existe uma única forma de inverter as aulas:

Um dos métodos de inversão de sala de aula mais difundidos no ensino de Física, o Instrução pelos Colegas (Peer Instruction), teve origem na década de 1990. Outros métodos, como o Ensino sob Medida (Just-in-Time Teaching), Aprendizagem Baseada em Equipes (Team Based Learning), Aprendizagem Baseada em Projeto (Project-Based Learning) e Aprendizagem Baseada em Problemas (Problem-Based Learning) têm origem entre as décadas de 70 e 90 [19].

Em aulas tradicionais é comum observar que o professor assume a função de transmissor de informação, consumindo um tempo considerável com exposição oral e resolução de exercícios. No entanto, a propagação de informações pode ser feita de maneira mais eficiente, o estudante pode acessar a informação com poucos toques em seu smartphone [19].

O isolamento social, decorrente da pandemia do novo Coronavírus, acarretou em diversas mudanças no nosso cotidiano, dentre elas, aquelas relacionadas à educação. Nesse âmbito, o ensino presencial teve que ser interrompido dando lugar ao ensino remoto. Para um melhor aproveitamento do ensino realizado em um ambiente virtual, se faz necessário o uso de metodologias que dinamizem o processo de ensino-aprendizagem a fim de promover uma aprendizagem mais significativa. Além de ser utilizada no ensino presencial, a metodologia da sala de aula invertida ganha espaço nessa modalidade de ensino. Ela permite ao aluno uma maior autonomia, descentralizando do professor o processo de ensinoaprendizagem.

\section{O Movimento Ondulatório e as Ondas Sonoras}

Como o nosso tema é poluição sonora, a base física é o ensino do som, que é uma onda. Há uma riqueza de aspectos que podem ser tratados, adequando assim ao nível e contexto dos alunos. Lembramos aqui alguns aspectos.

Apesar de conhecermos e utilizarmos palavras referentes a ondas no cotidiano, entretanto passar desse ponto para um conjunto de conhecimentos sistemáticos e que possam ser quantificados, na maioria das vezes, não é uma tarefa simples. Como ponto de partida, uma onda pode ser entendida como qualquer sinal que se propaga de um ponto ao outro num determinado meio, essencialmente levando energia sem que haja transporte direto de matéria.

As ondas sonoras são familiares e estão presentes em todo nosso cotidiano por meio de objetos que produzem sons. Os sons podem ser produzidos, por exemplo, através de choques entre dois corpos ou por instrumentos musicais que produzem melodias. Por ser uma onda mecânica, necessita de um suporte material para a sua propagação, que, portanto, não ocorre no vácuo.

Em escala microscópica, a propagação de ondas mecânicas deve-se a interações entre os átomos, fazendo com que o movimento seja transmitido pelas suas vizinhanças. Entretanto, não há transporte de matéria ao longo do meio, mas as partículas podem se deslocar, vibrando em torno de suas posições de equilíbrio. Relacionando as direções de propagação da onda com as do movimento das partículas do meio em que ela se propaga, ela será classificada como transversal se essas direções forem perpendiculares e longitudinal quando forem paralelas, caso em que o movimento das partículas será ao longo da direção de propagação.

Uma onda sonora pode ser descrita de quatro maneiras: em termos de mudanças na pressão, em termos de deslocamento de moléculas em relação às suas posições de equilíbrio, em termos da variação da massa específica do meio e em termos da velocidade de pequenos elementos do meio [20]. Embora tenham formas matemáticas diferentes, as descrições fornecem as mesmas informações.

Henrique [21, ressalta a importância fundamental do som puro, o mais elementar dos sinais para o estudo da acústica e no processamento de sinais em geral. A forma da onda desse tipo de som pode ser descrita de forma senoidal ou cossenoidal e sua característica é resultado de ser constituída de uma única frequência. De acordo com o teorema de Fourier, qualquer onda periódica de frequência fundamental f pode ser escrita em termos de uma soma de senos e cossenos. O som produzido por uma nota musical é sempre formado por uma frequência fundamental, que determina a altura do som, seguida de seus harmônicos superiores, que se forem de frequências múltiplas da fundamental, o som será harmônico. Cada uma das frequências que constitui um som complexo, isto é, composto por várias frequências, é denominada componente ou parcial. As ondas simples são aquelas de apenas uma frequência, que podem ser produzidas por aparelhos eletrônicos ou aproximadamente por um diapasão.

Quatro características são apresentadas pelas ondas sonoras [22]: altura, timbre, intensidade e duração. A altura, característica do som relacionada com a frequência, permite a distinção dos sons agudos (altas frequências) dos sons graves (baixas frequências). A faixa de $20 \mathrm{~Hz}$ a $20.000 \mathrm{~Hz}$ é a que o ouvido humano é capaz de perceber. 
O timbre é a propriedade que nos permite distinguir uma fonte sonora de outra, por exemplo, uma mesma nota musical que é reproduzida por instrumentos distintos. A intensidade do som, chamada popularmente de volume do som, está relacionada com a amplitude da onda sonora. Nas músicas, essa propriedade é indicada como pp (pianíssimo), p (piano), mf (meio forte), f (forte) e ff (fortíssimo). A duração é representada pelo tempo de duração do som. As notas musicais, numa música, possuem tempos diferentes. A duração é importante também, conforme explicitada na NR 15 8, citada anteriormente. Como a sensibilidade do ouvido varia com a frequência, em uma mesma intensidade, variando a frequência, a percepção é de que a intensidade também variou.

Conforme as possibilidades da turma, é interessante distinguir as grandezas intensidade do som, dada em $\mathrm{W} / \mathrm{m}^{2}$, e nível de intensidade sonora (ou nível de pressão sonora), dada em dB, e suas respectivas expressões matemáticas [22]. O sonômetro mede nível de pressão sonora (ou nível de intensidade sonora) e não intensidade.

\section{Proposta de Aulas Usando a Poluição Sonora e Resultados}

No sentido de apresentar uma proposta de atividade didática contemporânea, voltada para a formação do estudante para o exercício pleno da cidadania, propomos atividades que visam evidenciar as aproximações entre a Física e a Poluição sonora. Para tal, sua aplicação será realizada por meio de uma atividade didática que se inicia com uma pergunta com respeito à relação entre a Física e a poluição sonora nos fones de ouvido, que são muito usados pelos estudantes.

Diante da pergunta inicial os alunos na primeira etapa da aula devem responder um questionário investigativo cujo intuito é conhecer suas concepções prévias em relação ao assunto, servindo como base para construção do conceito físico a ser abordado. Para dinamizar essa primeira etapa, o questionário poderá ser respondido por meio do aplicativo Socrative 23], no qual o aluno participará de uma sala virtual tendo acesso somente às próprias respostas. Sugerimos algumas perguntas como: Quais os principais tipos de poluição? O que é poluição sonora? O que são ruídos? Existem limites de ruídos tolerados? Como é feita a medida de um ruído? Cite exemplos de fontes de poluição sonora. O que é o sonômetro? Existe fiscalização sobre sons intensos? Caso afirmativo, como é realizada? Que fatores contribuem para uma significativa perda auditiva? O uso contínuo de fones de ouvido no volume máximo pode contribuir para perda de audição? Como prevenir a perda auditiva? Além da perda auditiva, a poluição sonora pode gerar mais algum problema de saúde?

Inicialmente o professor fará uma introdução às ondas e ondas sonoras, incluindo as características físicas do som. Uma opção para o estudo das ondas mecânicas e das ondas sonoras está no Youtube, no canal do Prof. Luiz Pugginelli Brandão, que apresenta experimentos com materiais simples, que podem ser reproduzidos na escola, pelos alunos, ou simplesmente apresentados em vídeo 24 .

Nessa etapa ele apresenta algumas simulações com Phet simulation [25] (Ondas na corda, Interferência de ondas e Som). A partir daí, começará a problematização da temática poluição sonora. Para tanto, com o uso de recursos multimídia, o professor coloca os alunos frente à legislação, imagens e vídeos do cotidiano, onde aparecem situações nas quais estamos expostos à poluição sonora, assim como suas consequências a curto, médio e longo prazo.

Em seguida é interessante o professor solicitar aos alunos que se organizem em grupos (mais ou menos 4 alunos) para discutirem entre si sobre suas respostas e que cheguem a um consenso. Após essa etapa, o professor reproduz para a turma alguns vídeos que apresentam situações com poluição sonora. Sugerimos: "Ouça o som do Trânsito em uma Grande Cidade" [26], "São Paulo - O barulho da cidade" 27, "Britadeira na Madrugada" 28] e "Ambulância do SAMU no dia a dia" [29], todos disponíveis na internet.

É importante que haja ao término de cada vídeo uma rodada de discussão, na qual o professor poderá complementar informações e lançar novos questionamentos.

A fim de enriquecer o debate sobre as diversas fontes de poluição sonora, bem como uma conscientização sobre as causas, os danos e as possibilidades de intervenção dos cidadãos, é proposta aos alunos, como atividade extraclasse, a leitura de textos relativos à temática. Sugerimos o texto "Organização Mundial da Saúde considera poluição sonora, um problema de saúde pública", disponível na internet 30 .

A segunda aula inicia-se com a reprodução de vídeos que complementam o conteúdo da leitura sugerida ao término da aula anterior. Em seguida, o professor propõe aos alunos um momento de reflexão sobre as respostas fornecidas anteriormente no questionário investigativo, de modo que, caso seja necessário, o novo conhecimento adquirido seja utilizado em sua reformulação.

Os alunos devem ser estimulados a apresentar suas opiniões oralmente, de maneira que seja criado um clima de debate (argumentação e contra argumentação) por no máximo 5 minutos para cada pergunta. A fim de construir a resposta científica com os alunos, o professor propõe que eles acompanhem a realização de um experimento no qual, com o uso de sonômetro, devem fazer a medida do nível de intensidade sonora dos seus fones de ouvido de forma gradativa, ou seja, a partir do volume mínimo até chegar ao máximo, para perceberem que não é conveniente usar o volume máximo para ouvir suas músicas. Se o professor não tiver um sonômetro disponível, poderá utilizar um aplicativo de smartphone (indicamos o chamado Decibelímetro), que 
dará uma ideia aproximada da variação do nível de pressão sonora.

Por fim o professor apresenta os aplicativos e sugere que os alunos instalem em seus smartphones: Afinador, Spectroide, Metrônomo, Decibelímetro e Wave Editor. Em seguida indica alguns experimentos que podem ser feitos com o uso dos aplicativos.

Essas aulas foram aplicadas em um colégio particular do Estado do Rio de Janeiro, numa turma de $3^{\mathrm{O}}$ ano do nível médio. As atividades podem ser aplicadas também no caso de ensino remoto.

Com a aplicação das atividades os alunos puderam compreender de forma ampla e contextualizada alguns dos aspectos do cotidiano relacionados à Física ondulatória, em especial às ondas sonoras e à poluição sonora. Não só pelos questionários aplicados antes e depois das atividades, mas também pelas observações feitas em sala diante das exposições e problematização, as atividades mostraram-se eficientes no que diz respeito a uma melhora na compreensão de alguns aspectos relacionados à poluição sonora e às suas implicações. Comparando as respostas dos questionários após a atividade com as respostas do início, por exemplo, observa-se que as respostas melhoraram levando em conta as perguntas feitas no questionário investigativo relativas a alguns aspectos da poluição sonora e suas implicações e efeitos no cotidiano.

Com isso, foi possível desenvolver nos alunos um pensamento crítico sobre as consequências da exposição a sons com intensidades elevadas, com destaque para os fones de ouvido que são bastante utilizados por eles.

Foi possível evidenciar a importância da Física para a compreensão do mundo que nos cerca e que ela não se resume a números, fórmulas e resolução repetitiva de exercícios.

Sendo assim, as aulas de Física podem ser propostas e ministradas de maneira mais reflexiva, baseadas em atividades problematizadoras, que possam contribuir para a construção de um conhecimento amplo e diversificado dessa disciplina, deixando um pouco de lado o modelo tradicional de ensino, no qual o aluno fica limitado a decorar fórmulas para serem aplicadas na resolução de exercícios que não fazem parte do cotidiano dele, provocando consequentemente uma rejeição ou até mesmo aversão à Física.

\section{Referências}

[1] Associação Brasileira de Normas Técnicas. NBR 16.313:2014. Acústica - Terminologia (Associação Brasileira de Normas Técnicas Rio de Janeiro, 2014).

[2] D.F.B. Zajarkiewicch, Poluição sonora urbana: principais fontes. Aspectos jurídicos e técnicos. Dissertação de Mestrado, Pontifícia Universidade Católica de São Paulo, São Paulo (2010).

[3] C. Clark, H. Sbihi, L. Tamburic, M. Brauer, L.D. Frank e H.W. Davies, Environ. Health Perspect. 125, 087025 (2017).
[4] S. Pattenden, Occup. Environ. Med. 58, 761 (2001).

[5] C. Assunta, S. Ilaria, D.S. Simone, T. Gianfranco, C. Teodorico, S. Carmina, S. Anastasia, G. Roberto, T. Francesco e R.M. Valeria, Intern. Journal of Hygiene and Environ. Health 218, 163 (2015).

[6] A. Gupta, A. Gupta, K. Jain e S. Gupta, The Indian Journal of Pediatrics 85, 300 (2018).

[7] V.F.M. Riveiro, Ruído e suas consequências para o adoecimento. Trabalho de conclusão, Universidade Federal do Rio Grande do Sul, Rio Grande do Sul (2010).

[8] MINISTÉRIO DO TRABALHO E PREVIDÊNCIA. NR-15: Atividades e Operações Insalubres - Anexo 1: Limites de Tolerância para Ruído Contínuo ou Intermitente. Brasília, 2020.

[9] Associação Brasileira de Normas Técnicas. NBR 10.151:2000, Acústica - Avaliação do ruído em áreas habitadas, visando o conforto da comunidade - Procedimento (Associação Brasileira de Normas Técnicas, Rio de Janeiro, 2000).

[10] Associação Brasileira de Normas Técnicas. NBR 10.152:2017. Acústica - Níveis de pressão sonora em ambientes internos e edificações (Associação Brasileira de Normas Técnicas, Rio de Janeiro, 2017).

[11] MINISTÉRIO DA EDUCAÇÃO. Base Nacional Comum Curricular. Brasília, 2018. Disponível em: http://portal .mec.gov.br/conselho-nacional-de-educacao/base-n acional-comum-curricular-bncc-etapa-ensino-medio, acessado em 20/08/2021.

[12] G.L. Ladeia, Revista Saúde e Meio Ambiente 9, 34 (2019).

[13] MINISTÉRIO DO MEIO AMBIENTE. Resolução/ CONAMA/N. ${ }^{\circ} 001$ e 002 de 08 de março de 1990. Brasília, 1990. Disponível em: http://conama.mma.gov.br/comp onent/sisconama/?view=atosnormativos, acessado em 20/08/2021.

[14] M.F. Oliveira, W.D. Fonseca e M. Avelar, em: Anais do XXVIII Encontro da SOBRAC - Sociedade Brasileira de Acústica (Porto Alegre, 2019).

[15] E. Landulfo, Meio Ambiente e Física (Editora Senac, São Paulo, 2005), p. 77.

[16] M.P. Leodoro e R.C. Santos, em: Anais do XVII Simpósio Nacional de Ensino de Física (São Luís, 2007).

[17] MINISTÉRIO DA EDUCAÇÃO, Parâmetros Curriculares Nacionais (Ensino Médio) Parte I e Parte III - Bases Legais. Brasília, 2000. Disponível em: http://portal.m ec.gov.br/seb/arquivos/pdf/blegais.pdf acessado em $20 / 08 / 2021$

[18] A. Pelizzari, M.L. Kriegl, M.P. Baron, N.T.L. Finck e S.I. Dorocinski, Rev. PEC, Curitiba 2, 37 (2001-2002).

[19] T.E. Oliveira, I.S. Araújo e E.A. Veit, Física na Escola, 14, 4 (2016).

[20] R. Resnick, D. Halliday e K.S. Krane, Física 2 (Ed. LTC, Rio de Janeiro, 2007), p. 147.

[21] L.L. Henrique, Acústica Musical (Ed. Fundação Calouste Gulbenkian, Lisboa, 2002), p. 177.

[22] M.L. Grillo e L.R. Perez, Física e Música (Ed. Livraria da Física, São Paulo, 2016), p. 22.

[23] https://www.socrative.com/, acessado em 20/08/2021.

[24] https://www.youtube.com/channel/UCHUTK-huSmb M4P9tuTDo6pg/videos, acessado em 17/08/2021. 
[25] https://phet.colorado.edu/pt_BR/simulations acessado em 17/08/2021.

[26] https://www.youtube.com/watch?v=DaQmk51yec4, acessado em 14/08/2021.

[27] https://www.youtube.com/watch?v=tubEqPtEUNo acessado em 14/08/2021.

[28] https://www.youtube.com/watch?v=MRdgo9UBTg0 acessado em 14/08/2021.

[29] https://www.youtube.com/watch?v=cr1ezyAHU_g acessado em 14/08/2021.

[30] http://www.proacustica.org.br/publicacoes/artigos-s obre-acustica-e-temasrelacionados/oms-considera-polu icao-sonora-problema-de-saude-publica.html, acessado em 14/08/2021. 